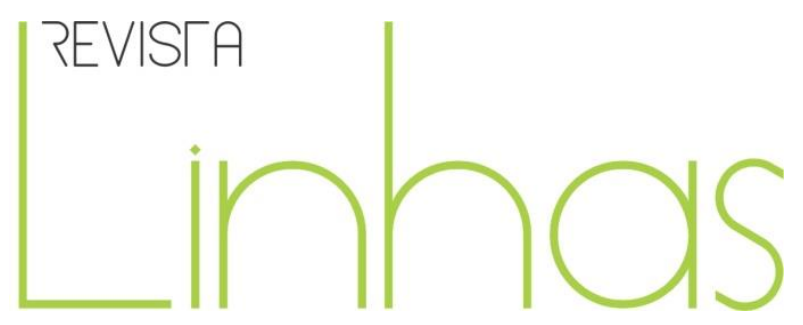

\title{
Ensino remoto na Universidade Federal do Pará: condições de estudo no campus universitário do Marajó-Breves
}

\begin{abstract}
Resumo
O objetivo deste artigo é analisar as condições de estudo no âmbito do Ensino Remoto Emergencial no Campus Universitário MarajóBreves, da Universidade Federal do Pará. Trata-se de pesquisa com abordagem quali-quantitativa que envolveu análise documental e aplicação de questionário on-line. Evidencia-se como a adoção do ensino remoto, no contexto da pandemia de Covid-19, impulsionada por ações do governo federal, atende aos interesses hegemônicos do capital, com consequências negativas para a educação pública. No caso da Universidade Federal do Pará, particularmente no Campus Universitário Marajó-Breves, o processo de implementação do ensino remoto não foi acompanhado da garantia das condições necessárias para a participação de toda comunidade estudantil. Grande parcela dos estudantes não possuía sequer equipamentos e acesso à internet adequados, utilizando-se predominantemente de aparelho celular e conexão de dados móveis para participar das atividades letivas remotas. Em suma, o ensino remoto, para além de favorecer interesses privado-mercantis, implica na precarização da educação pública e na ampliação da exclusão educacional.
\end{abstract}

Palavras-chave: Covid-19; ensino remoto; educação superior; universidade pública; condições de estudo.
André Rodrigues Guimarães

Universidade Federal do Amapá UNIFAP - Macapá/AP - Brasil andre_unifap@yahoo.com.br

\section{Cleide Carvalho de Matos}

Universidade Federal do Pará -

UFPA - Belém/PA - Brasil

cleidematos@ufpa.br

Maria da Conceição Rosa Cabral Universidade Federal do Pará -

UFPA - Belém/PA - Brasil mcrosa@ufpa.br

\footnotetext{
Para citar este artigo:

GUIMARÃES, André Rodrigues; MATOS, Cleide Carvalho de; CABRAL, Maria da Conceição Rosa. Ensino remoto na Universidade Federal do Pará: condições de estudo no campus universitário do Marajó-Breves. Revista Linhas. Florianópolis, v. 22, n. 49, p. 50-81, maio/ago. 2021.
} 


\title{
Emergency remote teaching at the Federal University of Pará: the study conditions at the Marajó-Breves university campus
}

\begin{abstract}
The purpose of this article is to analyze the study conditions within the ambit of Emergency Remote Teaching (ERT) at the Marajó-Breves University Campus of the Federal University of Pará. This study utilized a mixed methods approach that involved a documentary analysis and the application of an online questionnaire. Based on the data collected, it can be assured that the adoption of the ERT stimulated by the federal government due to the COVID-19 pandemic defends only the interests of capital, to the detriment of the negative consequences for public education. At least in the case of the Federal University of Pará, especially at the Marajó-Breves University Campus, the process of implementing remote teaching activities did not ensure the necessary conditions for the participation of the entire student population, because most students did not have appropriate equipment and nor internet access, so they needed to use a cell phone and mobile data connection to participate in the remote teaching activities. In sum, in addition to benefit the commercial interests, the ERT in the context of the COVID-19 pandemic leaded to more precariousness to the public education and contributed to the increase of educational exclusion.
\end{abstract}

Keywords: Covid-19; Emergency Remote Teaching (ERT); higher education; public university; study conditions. 
O ano de 2020 ficará marcado na história pela pandemia da Covid-19, provocada pelo novo Coronavírus, Sars-CoV-2. Em 30 de janeiro, a Organização Mundial da Saúde (OMS) declarou que a contaminação provocada por tal vírus atingiu o ápice de nível de alerta do Regulamento Sanitário Internacional; constituía-se, assim, em Emergência de Saúde Pública de Importância Internacional (ESPII). Dias depois, em 11 de março, a mesma OMS reconheceu a Covid-19 como uma pandemia, alcançando vários países e regiões do mundo (OPAS, 2021).

No Brasil, a proliferação e a letalidade da pandemia são alarmantes. Entre 26 de fevereiro, data de registro do primeiro caso, e 31 de dezembro de 2020, o país registrou 7.675.973 de casos confirmados e 194.949 óbitos; em 19 de abril de 2021, o número de casos alcançava 13.973.695 e o de óbitos 374.682, com letalidade em 2,7\% (BRASIL, 2021). Esses índices colocam o país entre os mais atingidos e os menos eficazes no combate à pandemia, fato que tem como elemento central o negacionismo científico, diretamente relacionado ao governo de extrema-direita de Jair Bolsonaro, que exime o Estado da responsabilidade de investimento na saúde pública (MOREL, 2021).

É também com a perspectiva de negação do papel estatal na garantia da educação pública que o governo federal regulamentou o ensino remoto no contexto da pandemia. No âmbito específico da educação superior, objeto do presente estudo, as mudanças legais foram ao encontro das políticas privatizantes instituídas no país desde a década de 1990. Esse processo trouxe implicações para as instituições públicas que, no contexto pandêmico, suspenderam as atividades presenciais e implementaram o ensino remoto.

Neste artigo, avaliamos algumas das implicações desse processo. Nosso objetivo consiste em analisar as condições de estudo no âmbito do Ensino Remoto Emergencial (ERE) no Campus Universitário Marajó-Breves (CUMB) da Universidade Federal do Pará (UFPA). Para tanto, realizamos pesquisa com abordagem quali-quantitaiva, envolvendo análise documental e pesquisa de campo. Na análise documental, consideramos a legislação nacional, normativas e diagnósticos produzidos pela UFPA. Na pesquisa de campo, trabalhamos com dados levantados por meio de questionário on-line com 174 estudantes do CUMB/UFPA. 
O artigo, além desta introdução e da conclusão, tem quatro seções. Na primeira, analisamos a regulamentação do ensino remoto na educação superior brasileira. $\mathrm{Na}$ segunda, exploramos a instituição do ERE na UFPA. Na terceira e quarta, discutimos a efetividade desse processo, com destaque para a análise de dados levantados na pesquisa de campo, particularmente, em relação à infraestrutura, à Assistência Estudantil e aos meios e condições de acesso à internet no ERE.

\section{Regulamentação do ensino remoto na educação superior brasileira}

Antes de analisarmos a implantação do ensino remoto na educação superior brasileira, particularmente no âmbito da UFPA, é necessário considerarmos o cenário de atendimento nesse nível de ensino. Isso evidenciará como as ações estatais em tal âmbito estão diretamente articuladas com as políticas em curso no país, as quais estão em consonância com os interesses hegemônicos do capital. Fundamental observarmos que, desde meados da década de 1990, vivenciamos um processo de expansão privadomercantil na educação superior brasileira (SGUISSARDI, 2009). Esse movimento é parte da adequação das políticas públicas aos atuais interesses produtivos do capitalismo. Com a crise estrutural do capital (MÉSZÁROS, 2009), desencadeada a partir da década de 1970, redimensionou-se o papel do Estado no atendimento às demandas sociais. Em síntese, fundamentados na defesa do livre mercado, reduz-se a função estatal na manutenção de políticas sociais e amplia-se seu intervencionismo como garantidor da valorização do capital: trata-se da hegemonia neoliberal (HARVEY, 2008).

Com base nesses princípios, organismos multilaterais, representantes do capital, assumem o protagonismo de planejar globalmente a formulação de políticas educacionais afeitas aos seus interesses. Conforme elucida Maués (2019), essas instituições, como o Banco Mundial (BM) e a Organização para a Cooperação e Desenvolvimento Econômico (OCDE), elaboraram (e continuam elaborando) documentos com orientações para viabilizar a reforma das políticas educacionais. Esse movimento ganha efetividade na América Latina a partir da década de 1990; no caso brasileiro, consolida-se a partir do governo Fernando Henrique Cardoso (1995-2002). 
No âmbito da educação superior isso implica no estabelecimento de políticas que incentivam o setor privado. Esse movimento perpassa pela flexibilização da legislação, a partir da Lei no 9.394/1996, Lei de Diretrizes e Bases da Educação Nacional - LDB (BRASIL, 1996), particularmente, com o estímulo à expansão de Instituições de Ensino Superior (IES) privadas não universitárias (CHAVES, 2010), bem como com a concessão de subsídios públicos, via isenção fiscal e financiamento estudantil (MANCEBO; VALE; MARTINS, 2015). Tais ações, para além de ampliarem o predomínio da privatização, conduzem à mercantilização da educação superior: o privado assume explicitamente um caráter mercantil, diretamente relacionado à valorização do capital.

Nessa esteira, conforme elucidam Chaves, Santos e Kato (2020), as políticas estatais que subsidiam o setor privado estimulam a financeirização e oligopolização da educação. Desse modo, ações como o Financiamento Estudantil (Fies) e o Programa Universidade para Todos (Prouni), ademais de ampliarem o atendimento educacional privado, servem diretamente, concluem as autoras, para valorizar grandes grupos empresariais em suas ações nas bolsas de valores. Efetivamente, a educação perde qualquer perspectiva de formação humana para submeter-se à lógica estritamente mercantil.

Para viabilizar a valorização do capital há uma condição basilar: reduzir os custos com a sua produção. Esse processo tem sua centralidade na ampliação das taxas de maisvalia, com intensificação da exploração da força de trabalho (MARX, 1984). Entre outras medidas, para o capital faz-se necessário aumentar produtividade e precarizar o trabalho. No caso da empresa educacional isso se expressa em maior número de clientes/estudantes atendidos e em menor número de trabalhadores, preferencialmente sem direitos trabalhistas.

Como parte das medidas governamentais que viabilizam a expansão dessa concepção de formação está a regulamentação da Educação a Distância (EaD). Como demonstram Evangelista et al. (2019), essa modalidade é fomentada inicialmente no interior das IES estatais, para, em seguida, ganhar força no âmbito do mundo empresarial, assumindo, nos últimos anos, o modo expansionista privilegiado do setor privado. Dados do Censo da Educação Superior evidenciam a acentuada contribuição da EaD para manutenção da ampliação das matrículas no setor privado-mercantil, entre 2011 e 2019, 
com índice de 31,4\%. As matrículas em cursos presenciais apresentaram o irrisório crescimento de 1,9\%, inclusive com registro de queda a partir de 2016. As matrículas em cursos EaD tiveram evolução positiva constante, alcançando no período, expansão de 181,3\%. Como consequência, a EaD tornou-se responsável, em 2019, por 35,1\% do total das matrículas privadas (INEP, 2020).

Esse contexto não pode ser ignorado ao analisarmos a instituição do ensino remoto, ainda que com a alcunha de emergencial, em função do impedimento das aulas presenciais na pandemia. Conforme será evidenciado neste estudo, documentos oficiais enfatizam que a utilização de aulas remotas na educação superior é favorecida pela expertise do país em EaD. Em 2020, no contexto da pandemia, o Ministério da Educação (MEC) publicou sete Portarias para regulamentar a substituição das atividades letivas presenciais pelo ensino remoto na educação superior. O Conselho Nacional de Educação (CNE) aprovou seis Pareceres e uma Resolução que também regulamentam a matéria. $\mathrm{E}$ ainda foi instituída Medida Provisória (MP), convertida em Lei, com flexibilização do quantitativo de dias letivos definidos na LDB.

Preliminarmente, é possível identificarmos duas características na regulamentação do ensino remoto. A primeira diz respeito à insegurança governamental na definição desse processo, pois em distintas situações as Portarias foram retificadas em curto prazo de tempo e três Pareceres foram apenas com reexame de pontos tratados em outros três Pareceres. A segunda refere-se à ausência de compreensão do governo sobre a gravidade e extensão temporal da pandemia, pois em duas Portarias apenas prorrogou-se a vigência das anteriores. Essas questões evidenciam a inoperância governamental no enfrentamento à crise de saúde instituída no país e o descaso com a educação pública.

Ao analisarmos o conteúdo das Portarias do MEC, verificamos que em 2020 foram apenas dois documentos que de fato estabeleceram normas sobre o ensino remoto na educação superior. A primeira foi a Portaria no 343 , de 17 de março de 2020 (BRASIL, 2020a), com pequenas alterações feitas pela Portaria no 345, de 19 de março de 2020 (BRASIL, 2020b). A Portaria no 395, de 15 de abril de 2020 (BRASIL, 2020C), e a Portaria no 473, de 12 de maio de 2020 (BRASIL, 2020d), apenas prorrogaram a vigência do estabelecido nas anteriores. A segunda foi a Portaria no 544, de 16 de junho de 2020 (BRASIL, 2020e), que passou a regulamentar o tema até 21 de fevereiro de 2021. Essa 
Portaria foi revogada, a partir de 04 de janeiro de 2021, pela Portaria nº 1.030, de 01 de dezembro de 2020 (BRASIL, 2020f), porém foi reativada, dias depois, com a Portaria no 1.038, de 7 de dezembro de 2020 (BRASIL, 2020g)'.

A Portaria nº 343, em seu artigo 1을 definiu por "Autorizar, em caráter excepcional, a substituição das disciplinas presenciais, em andamento, por aulas que utilizem meios e tecnologias de informação e comunicação, nos limites estabelecidos pela legislação em vigor, por instituição de educação superior integrante do sistema federal de ensino [...]" (BRASIL, 2020a, grifo nosso). A Portaria nº 345 retirou o trecho "nos limites da legislação em vigor", reconhecendo que a regulamentação era arbitrária e não possuía amparo legal e permitiu a inclusão dos cursos de Medicina, com uma ressalva: "apenas às disciplinas teóricas-cognitivas do primeiro ao quarto ano do curso" (BRASIL, 2020b).

A Portaria no 544 amplia a abrangência das Portarias anteriores. Permite a adoção de disciplinas novas, ainda não ofertadas; substitui o termo "aulas" por "atividades letivas" e inclui a utilização de "outros meios convencionais" para substituir as atividades presenciais (BRASIL, 2020e). A flexibilização também se manifesta no §2º do Art. 1ํㅜ no lugar de "disciplinas" amplia-se para "componentes curriculares" e os "conteúdos ofertados" passam a ser "atividades letivas ofertadas". Em síntese, na prática, passa-se a permitir na oferta regular dos cursos presenciais que atividades diversas, "não convencionais", sejam consideradas componentes que substituem os conteúdos curriculares.

Tal processo foi acompanhado de posições favoráveis do CNE. No Parecer CNE/CP no 05/2020 (BRASIL, 2020h), aprovado em 28 de abril, primeiro do órgão a tratar do tema, é explícita a defesa da utilização de atividades remotas em substituição às aulas presenciais. Nesse e nos demais Pareceres sobre o tema é exaltada a "expertise" que temos em EaD na educação superior:

[...] os dados do censo demonstram a expertise e a maturidade da Educação a Distância em cursos superiores. Essa realidade facilita o cumprimento das Portarias MEC nos 343/2020 e 345/2020 e nos convidam ao entendimento e proposição de um largo uso dessa modalidade como forma de continuidade das atividades de ensino e aprendizado. Nos

\footnotetext{
${ }^{1}$ Em função da delimitação do ERE na UFPA, setembro de 2020 a fevereiro de 2021, não consideraremos para análise neste estudo as duas últimas Portarias.
} 
convida, inclusive, a reinterpretar os limites de aulas e outras atividades acadêmicas que podem ser ofertadas a distância. (BRASIL, 2020h, p. 16)

Essa perspectiva coaduna-se com o esvaziamento da formação acadêmica. Tratase de consolidar a educação de acordo com a lógica do capital humano, na qual o conhecimento tem seu valor atribuído em função da sua utilidade para o trabalho precário. Isso também implica na responsabilização individual pela aquisição dos atributos, habilidades e competências, para manter-se disponível à empregabilidade e ao empreendedorismo.

No conjunto de seus documentos, o CNE ressaltou não ser plausível impedir a realização de práticas e estágios de forma remota. Em consonância com esse entendimento, a Portaria no 544 também incluiu a possibilidade das "práticas profissionais de estágios e de laboratório" serem realizadas de forma não presencial. O texto ainda destaca que caso o Projeto Pedagógico do Curso não preveja essa possibilidade de substituição, "deve constar de planos de trabalhos específicos, aprovados, no âmbito institucional, pelos colegiados de cursos e apensados ao projeto pedagógico do curso" (BRASIL, 2020e). Assim, induz-se a mudanças abruptas, sem o debate acadêmico necessário, nos Projetos Pedagógicos.

Cabe destacarmos que, antes mesmo de ser publicada a Portaria $\mathrm{n}^{\circ}$ 544, 0 Presidente da República editou a MP no 934/2020 (BRASIL, 2020i), publicada em 1o de abril, alterando a LDB, com a flexibilização do ano letivo da educação básica e do ensino superior. Segundo essa normativa, as IES ficavam dispensadas, excepcionalmente, no contexto da pandemia, de observar o mínimo de dias letivos de efetivo trabalho acadêmico. Tal MP foi convertida na Lei noํ⒕040/2020 (BRASIL, 2020j), sancionada em 18 de agosto que, em essência, manteve a flexibilização, mas definiu que caberia ao CNE editar diretrizes nacionais para implementação do estabelecido na Lei.

A migração da educação presencial para as plataformas digitais de aprendizagem é um caminho que vinha sendo trilhado no âmbito do MEC. A partir da Portaria $\mathrm{n}^{\circ} \mathrm{2} 2.117$, de 6 de dezembro de 2019 (BRASIL, 2019), as IES pertencentes ao Sistema Federal de Ensino poderiam utilizar até $40 \%$ da carga horária dos cursos presenciais na modalidade EaD. Possibilidade essa exaltada pelo CNE como estratégia para evitar a necessidade de 
reposição de aulas na forma presencial (BRASIL, 2020k). Assim, a pandemia criou o cenário ideal para a implementação de EaD nos cursos presenciais de graduação também nas Universidades Federais.

Os posicionamentos expressos nas Portarias do MEC e nos Pareceres do CNE foram consolidados na Resolução CNE/CP N², de 10 de dezembro de 2020 (BRASIL, 2020l). Evidencia-se, assim, que a utilização do ensino remoto no contexto pandêmico reforça o projeto de utilização da EaD como modalidade privilegiada de oferta da educação superior. Contudo, outro aspecto merece destaque na análise da legislação: a isenção, por parte do MEC, da garantia de condições necessárias para implementação das mudanças nas instituições federais. Em todos os documentos fica explícita a responsabilidade das IES em garantir condições que permitam os estudantes acompanharem as atividades letivas. Importante observar que tal desresponsabilização por parte do MEC afina-se à política de cortes do orçamento nas políticas sociais, imposta pela Emenda Constitucional no 95/2016 (BRASIL, 2016). Também em decorrência disso, por exemplo, o orçamento das universidades federais em 2020 foi inferior ao praticado em 2019 (REIS; MACÁRIO, 2020). Logo, para além das implicações pedagógicas, esse processo tende a se efetivar sem a viabilidade das condições materiais necessárias.

Assim, para além de fortalecer a perspectiva privatista de educação, com defesa da utilização da EaD como equivalente à educação presencial, a implementação do ensino remoto nas IES públicas, conforme orientação do MEC, esvazia a concepção de formação acadêmica e agudiza as desigualdades de acesso e permanência. Afina-se, desse modo, ao projeto neoliberal: ampliação do mercado, com a individualização da responsabilidade pela aquisição do conhecimento e, consequentemente, com a omissão do papel estatal. Nas seções seguintes, veremos a materialização desse processo na UFPA, particularmente, no CUMB.

\section{Ensino Remoto Emergencial na Universidade Federal do Pará}

A UFPA é uma instituição federal de educação superior, criada há 63 anos na capital do estado do Pará. Atualmente, com uma estrutura multicampi, a UFPA é considerada a maior universidade pública da Amazônia, com 12 campi - incluindo capital e 
interior - que abrigam em sua totalidade 14 institutos, sete núcleos, dois hospitais universitários e uma Escola de Aplicação. No relatório de 2020 (ano base 2019), contava com 2.488 docentes, 2.539 Técnicos-Administrativos em Educação e 48.810 estudantes (de graduação e pós-graduação), tornando-a uma das maiores universidades do país em número de estudantes (UFPA, 2020a).

Com o aumento do número de casos de Covid 19 e o registro do primeiro óbito no país, ainda na primeira quinzena de março, foi instalado um Grupo de Trabalho na UFPA sobre o novo Coronavírus, com o objetivo de acompanhar a evolução do cenário epidemiológico da doença e divulgar recomendações à comunidade acadêmica (UFPA, 2020b)². Assim, levadas em consideração as orientações de autoridades sanitárias e as recomendações desse Grupo de Trabalho - e a exemplo de outras instituições de ensino público -, as atividades acadêmicas e administrativas presenciais na UFPA foram suspensas por decisão da Administração Superior. Inicialmente, suspensas de 19 de março até 12 de abril de 2020, mas diante do quadro pandêmico, o reitor decidiu pela manutenção da suspensão das atividades presenciais, desta vez por tempo indeterminado, ato referendado pelo Conselho Superior de Ensino e Pesquisa (Consepe), em 22 de maio, por meio da Resolução no 5.291/2020 (UFPA, 2020C). Na ocasião, foi instituída uma Comissão Acadêmica ${ }^{3}$ que deveria se apropriar das experiências, debates e legislação sobre o ERE, com vistas ao acompanhamento e proposição de ações - a serem apreciadas pelo Consepe - sobre o futuro retorno das atividades acadêmicas, tão logo fosse possível e seguro para todos (UFPA, 2020d).

Vale ressaltar que em matéria publicada pela Assessoria de Comunicação da UFPA, o reitor, professor Emmanuel Tourinho, afirmou que “[...] as decisões sobre calendário e sobre atividades de ensino devem levar em conta duas referências: a garantia da qualidade das atividades e a garantia de que nenhum discente seja prejudicado." (UFPA, 2020d). Esse excerto torna-se importante na contextualização de uma pesquisa em um campus da UFPA no interior do estado - onde a qualidade de internet deixa muito a desejar - sediado em um município com baixo Índice de Desenvolvimento Humano (IDH) (GONÇALVES; COSTA, 2020).

\footnotetext{
${ }^{2}$ Cf. <https://coronavirus.ufpa.br/1/recomenda\%C3\%A7\%C3\%B5es>.

${ }^{3}$ A comissão foi composta, inicialmente, por conselheiros do Consepe; depois foi ampliada.
} 
A composição da comissão que deveria pensar estratégias para um possível retorno às atividades acadêmicas contava com representantes dos 12 campi da UFPA entre docentes, técnicos e discentes - e com representantes dos sindicatos dos docentes e dos Técnicos-Administrativos em Educação. Assim, passando a integrar esse grupo de trabalho, a Associação dos Docentes da Universidade Federal do Pará (ADUFPA) reuniu os docentes em Assembleia Geral que deliberou de forma contrária ao Ensino Remoto, destacando entre as justificativas ser inaceitável qualquer proposta que não se pautasse pelo princípio da inclusão de todos/as (ADUFPA, 2020). Importa ressaltar que a Associação defendia a realização de atividades formativas on-line para os estudantes, desde que fossem sem caráter obrigatório; não curriculares; que elegessem temas de interesse à universidade e à sociedade; que envolvessem estudantes, docentes, servidores técnico-administrativos e a sociedade em geral (ADUFPA, 2020).

No processo de acompanhamento e proposição de ações para implantar o que viria a ser chamado de Período Letivo Emergencial, a comissão definiu Ações Preparatórias e de Diagnóstico. No âmbito do diagnóstico foram realizadas pesquisas de levantamento com estudantes, docentes e gestores de faculdades, colegiados e com os Núcleos Docentes Estruturantes dos Cursos $^{4}$. A pesquisa com os estudantes foi realizada no período de 23/07 a 13/08/2020, por meio da aplicação de um questionário on-line intitulado Uso de Tecnologias Digitais de Informação e Comunicação (TDICs) por discentes em tempos de covid-19 (UFPA, 2020e). O objetivo era levantar o perfil tecnológico/digital, incluindo a existência e qualidade do acesso digital dos estudantes (UFPA, 2020f).

De um universo de 41.626 discentes matriculados nos últimos quatro períodos letivos (dois últimos anos), foram obtidas 8.041 respostas. Um cenário desfavorável à implantação do ensino remoto foi evidenciado pelos dados; alguns deles, trazemos aqui. Um primeiro é a renda per capita dos discentes. O levantamento mostrou que $63 \%$ dos respondentes possuíam renda familiar de até $\mathrm{R} \$ 1.567,50$, sendo que $20 \%$ tinham renda de até 1,5 salário-mínimo; $27 \%$ de até um salário-mínimo; e $16 \%$ de até meio salário-mínimo. Outro dado que possui relação direta com o primeiro, diz respeito ao custo com os estudos: $33 \%$ dos discentes se deslocavam diariamente ou semanalmente para o

\footnotetext{
${ }^{4}$ Apenas o resultado do levantamento com estudantes e docentes foi divulgada, em forma de relatório síntese, via e-mail institucional.
} 
município onde funciona o campus da UFPA, o que pressupõe gastos e comprometimento da renda familiar. Um terceiro fator diz respeito ao acesso à internet. Embora a grande maioria possuísse equipamentos (smartphone; tablet; notebook e desktop), uma fração significativa (41\%) tem como principal local de acesso à internet o trabalho, o estágio, a casa de parentes, o campus universitário ou outras redes públicas, o que muito restringe o acesso às aulas.

Esses três fatores - renda, custos com estudo e local de acesso à internet - são desfavoráveis à adesão ao ensino remoto, pois a falta de acessibilidade digital excluiria muitos estudantes do processo de ensino. Em nossa avaliação, os dados aqui apresentados se constituiriam em obstáculos para a implantação do ensino remoto na UFPA, mas parece terem sido desconsiderados pelo Consepe em sua decisão pela aprovação do ERE. Os estudantes demandariam um certo apoio, fosse ele financeiro ou técnico. Esse apoio seria dado com oferta de cursos de formação e com auxílio de inclusão digital a estudantes.

No dia 23 de julho, em reunião do Consepe, as discussões acumuladas na Comissão instituída no Consepe e no âmbito das Unidades Acadêmicas - aprovadas nos órgãos máximos de deliberação em cada Unidade ${ }^{5}$ - foram apresentadas em uma Minuta de Resolução que orientaria o retorno das atividades acadêmicas curriculares por meio do ensino remoto. Em reunião extraordinária do Consepe, em 21 de agosto de 2020, a UFPA aprovou a implantação transitória do ERE, regulamentada pela Resolução no 5.294/2020 (UFPA, 2020g), cuja ementa ficou assim definida: “Aprova, de forma excepcional e temporária, o Ensino Remoto Emergencial em diferentes níveis de ensino para os cursos ofertados pela Universidade Federal do Pará, em decorrência da situação de pandemia do novo Coronavírus-COVID-19, e dá outras providências."6

$\mathrm{Na}$ continuidade das ações para o retorno às atividades acadêmicas, reconhecendo a necessidade de dar suporte aos estudantes com dificuldades de acesso ao ERE, a Superintendência de Assistência Estudantil (SAEST) publicou editais específicos

\footnotetext{
${ }^{5}$ Congregação de Unidades e Conselhos de Campi são órgãos máximos de deliberação nas unidades.

6 Cabe ressaltarmos ainda que a Resolução Consepe 5.294/2020 (UFPA, 2020g) teve vigência até 28 fevereiro de 2021. A partir de então, as atividades de ensino passaram a ser regidas por nova normatização, que manteve, entre outras questões, a possibilidade de aulas remotas no contexto pandêmico.
} 
para apoio à inclusão digital7. Assim, em 31 de julho de 2020, saiu o Edital № 06/2020/SAEST/UFPA (UFPA, 2020h), referente à concessão de Auxílios Emergenciais de Apoio à Inclusão Digital (Auxílios $\mathrm{TIC} / 2020$ ) - Modalidades I e $\mathrm{II}^{8}$, para discentes de graduação, pós-graduação e do Ensino Básico da UFPA em vulnerabilidade socioeconômica. De um total de 12.958 estudantes inscritos, foram selecionados 5.638 (43,5\%) na Modalidade I, e 3.500 (27,0\%) na modalidade II. Para a modalidade II, ainda houve um cadastro reserva de 3.567 estudantes (UFPA, 2020i). Em 30 de outubro de 2020, a UFPA tornou público mais um edital, o de $N^{\circ}$ 10/2020 - SAEST/UFPA (UFPA, 2020j), voltado à concessão de Auxílio Emergencial de Apoio à Inclusão Digital aos discentes em vulnerabilidade socioeconômica, mais especificamente, à concessão de chips para acesso à internet ${ }^{9}$.

Na perspectiva do atendimento à Tecnologia Assistiva, houve ainda concessão do “Auxílio Kit PcD de Tecnologia Assistiva”, com vistas a atender discentes com deficiência (física, intelectual, auditiva, visual e Transtornos do Espectro Autista) regularmente matriculados na Educação Básica, cursos de graduação ou pós-graduação stricto sensu da UFPA, em situação de vulnerabilidade socioeconômica. Tal auxílio seria contemplado por dois editais. O processo seletivo regido pelo Edital $\mathrm{n}^{\circ}$ 07/2020/SAEST/UFPA, de 9 de setembro de 2020 (UFPA, 2020k), de um total de 166 inscritos, selecionou 18 discentes com deficiência $(10,8 \%)$ vinculados aos cursos de graduação e pós-graduação da UFPA. O processo seletivo previsto no Edital no 09/2020/SAEST/UFPA, de 13 de outubro de 2020 (UFPA, 2020l), selecionou 28 discentes com deficiência $(20,7 \%)$ vinculados à Escola de Aplicação e cursos de graduação da UFPA, de um total de 135 inscritos. Ambos se destinavam à aquisição de equipamentos dispostos no Plano de Aplicação de Proposta Orçamentária individualizado apresentado pelo discente, com recurso de até $\mathrm{R} \$ 3.000,00$ por aluno (UFPA, 2020i) $)^{10}$.

\footnotetext{
7 Cf. https://saest.ufpa.br/portal/index.php/component/content/article?id=2348.

${ }^{8}$ Modalidade I, pacotes de dados móveis de serviço móvel pessoal, e Modalidade II, concessão de auxílio financeiro no valor de $\mathrm{R} \$ 1.200,00$.

${ }^{9}$ Até a conclusão deste artigo, não tivemos acesso aos números de inscritos e contemplados pelo Edital $\mathrm{N}^{\circ}$ 10/2020 - SAEST/UFPA (UFPA, 2020i).

${ }^{10}$ Além dos editais voltados mais especificamente à inclusão digital no ERE, a SAEST divulgou, em 2020, outros editais de processos seletivos do Programa Permanência vinculado ao Programa Nacional de Assistência Estudantil (PNAES), para custeio parcial ou integral de alimentação, transporte, material didático e/ou moradia.

Disponível

em:
} 
Tomando o número de interessados no auxílio previsto nos editais, vemos que muitos estudantes ficaram de fora do processo, e aqui retomamos a manifestação do reitor sobre o retorno às atividades acadêmicas durante a pandemia, indicando a necessidade de garantia da qualidade das atividades e que nenhum estudante seria prejudicado. Na prática, isso foi desconsiderado como parâmetro para a implantação do ERE. Embora o § $2^{\circ}$ do Artigo 4 da Resolução 5.294/2020 tenha estabelecido que "Caso a execução do auxílio para Inclusão Digital não tenha ocorrido até o dia 14 de setembro, a Reitoria da UFPA determinará nova data para início das atividades de Ensino Remoto Emergencial" (UFPA, 2020g), a entrega dos chips e recurso financeiro se deu somente após o início das aulas, sem que tenha sido determinada uma nova data para início das atividades acadêmicas. Há de se imaginar a situação de exclusão dos estudantes que, sem acesso à internet de qualidade, se matricularam no Período Letivo Emergencial 2020, bem como daqueles que nem mesmo ousaram se matricular.

Alguns atenuantes a essa exclusão digital foram estabelecidos na Resolução 5.294/2020, no Artigo $9^{\circ}$ e parágrafos. O discente que optasse por não cursar as disciplinas oferecidas no Período Letivo Emergencial 2020 e aguardar a sua oferta na modalidade presencial não teria seu percurso acadêmico interrompido; ficou suspensa a contagem do tempo para integralização curricular do curso até que seja reiniciada a oferta presencial das Atividades Curriculares; o discente poderia solicitar à coordenação do curso, a qualquer tempo e sem justificativa, o cancelamento da matrícula na modalidade de ERE; quem não alcançasse aproveitamento nas disciplinas ofertadas teria sua matrícula automaticamente cancelada (UFPA, 2020g).

\section{Ensino remoto no Campus Universitário do Marajó-Breves: do diagnóstico à implantação}

O Campus Universitário do Marajó-Breves é uma unidade regional da UFPA com sede na cidade de Breves e, desde 1990, vem ofertando curso de graduação, sobretudo no âmbito das licenciaturas. Atualmente integram esse campus cinco faculdades, quais sejam: Faculdade de Ciências Naturais, Faculdade de Educação e Ciências Humanas, Faculdade de Letras, Faculdade de Matemática e Faculdade de Serviço Social. O 
CUMB/UFPA atende estudantes oriundos de vários municípios do Marajó e inclusive de outras mesorregiões do Pará.

O período letivo de 2020 começou em janeiro com a oferta de disciplinas para as turmas do intensivo (2020.1)11 que se estendeu até fevereiro. Em março, começou o período 2020.2, com as turmas do regime extensivo; no entanto, ainda nas primeiras aulas, as atividades foram interrompidas em função da pandemia. A partir de então, o Campus realizou várias pesquisas para fazer um diagnóstico sobre o trabalho remoto, o acesso à internet e os impactos da pandemia na rotina de docentes, discentes e técnicos, com a finalidade de orientar as ações no que dizia respeito ao retorno às aulas. As pesquisas resultaram em sete relatórios ${ }^{12}$ e uma nota técnica sobre a pandemia no município de Breves. Neste artigo, em função dos seus objetivos, vamos trazer os resultados apresentados no Relatório de aplicação do questionário a discentes do CUMB (Usos tecnologia e acesso à Internet) (UFPA, 2020m).

A pesquisa Usos de tecnologia e acesso à internet teve como objetivo investigar as condições de uso e acesso à internet dos discentes do CUMB/UFPA para analisar a possibilidade de realizar atividades acadêmicas de modo remoto. O questionário foi respondido no período de 3 a 10 de julho de 2020, por 502 estudantes, de um total 1.175 com matrícula ativa no sistema. A pesquisa identificou que $60,9 \%$ dos discentes residiam em domicílios com três a cinco pessoas e a maioria (82,5\%) sobrevivia com rendimentos brutos mensais de até dois salários-mínimos. Isso indicava as dificuldades de implantação do ensino remoto no Campus, pois "[...] a vulnerabilidade econômica da população influencia e restringe o acesso à internet" (MARCON, 2020, p. 83). Uma vez que o orçamento familiar é mais voltado para o atendimento das necessidades básicas das famílias, sobretudo, a alimentação, e com a alta da inflação, o impacto no orçamento familiar dessas famílias é maior, comprometendo o atendimento de outras necessidades.

Em relação ao local de acesso à internet, $59 \%$ dos estudantes responderam que o faziam em suas residências. Porém, para $18,6 \%$ essa conexão se dava somente na

\footnotetext{
${ }^{11}$ A UFPA trabalha com quatro calendários, sendo dois para turmas que estudam em tempo integral, chamado de período intensivo, que compreende os meses de janeiro/fevereiro e julho/agosto, e dois calendários para turmas que estudam no período regular, de março a julho e de agosto a dezembro, denominados de período extensivo.

12 Os relatórios estão disponíveis no endereço: http://www.campusbreves.ufpa.br/index.php/outraspublicacoes.
} 
Universidade. Logo, dois em cada 10 estudantes, em média, estariam impedidos de acompanhar aulas remotas, pois, com o agravamento da pandemia, a Universidade encontrava-se fechada.

Pesquisa realizada pelo CETIC.BR, sobre TIC Domicílios 2019, constatou que o acesso à internet nos domicílios brasileiros se dá de forma desigual e que o poder aquisitivo das famílias determina as condições de acesso. Os dados evidenciaram que apenas $71 \%$ da população brasileira tinham acesso à internet e esse acesso se concentra nas classes sociais que possuem maior poder aquisitivo: as classes $A$, B e C têm acesso de 99\%, 95\% e 80\% respectivamente; por sua vez, nas classes D e E apenas 50\% têm acesso à internet no domicílio. Com base nesses dados, entendemos que qualquer modelo de educação que se pretenda implementar por meio do ensino remoto será excludente, pois não incluirá uma parcela significativa da população.

O diagnóstico feito pelo CUMB/UFPA identificou que o dispositivo utilizado por $92 \%$ dos estudantes para acessar à internet era o celular. No entanto, 52\% deles avaliaram que esse dispositivo não permitiria fazê-lo de forma satisfatória. Os dados da pesquisa com os discentes do CUMB/UFPA se aproximam dos resultados apresentados na pesquisa realizada pelo CETIC.BR que também identificou o celular como o dispositivo mais utilizado pelos usuários de internet. No período analisado, houve uma progressiva substituição do computador pelo celular entre os usuários de internet. Se, em 2014, o acesso à internet por celular correspondia a 76\% e por computador era de 80\%; em 2019, a utilização do celular chegou ao percentual de $99 \%$, enquanto o computador caiu para $42 \%$ (CETIC.BR, 2019).

Ainda em relação ao diagnóstico do CUMB/UFPA, existia um número significativo de discentes que não tinha dispositivo para acessar as plataformas digitais e as aulas online. Por sua vez, os que tinham acesso à internet conviviam com outro problema, qual seja, a instabilidade do sinal e os altos custos dos serviços ofertados, tanto os que usavam pacotes de internet móvel via chip, quanto os que utilizavam os serviços de internet banda larga fixa. Com relação às atividades que poderiam ser realizadas por meio da internet, os estudantes responderam: ouvir áudios, ler documentos on-line e assistir vídeos educacionais. De acordo com o Relatório (UFPA, 2020m), essas atividades foram 
mais frequentes por serem melhor adaptáveis às rotinas dos discentes, uma vez que não exigem um horário específico para serem realizadas.

As respostas sugerem uma educação nos moldes da EaD, cujas atividades são disponibilizadas em plataformas digitais e o aluno define o horário para acessá-las dentro de um prazo estabelecido. Embora seja preocupante a ideia de promover o ERE diante das desigualdades sociais e econômicas, a sugestão de desenvolvê-lo de forma totalmente a distância entra num campo ainda nevrálgico, que é a possibilidade de implementação da EaD nos cursos presenciais das universidades públicas, e a Resolução no $5.294 / 2020$, que aprova o ERE na UFPA, possibilitou tal organização do ensino.

Essa perspectiva poderia ganhar adesão na medida em que os estudantes não tinham condições de participar de aulas síncronas ou cumprir os prazos estabelecidos para entrega de atividades. Em relação à disponibilidade para participar das aulas síncronas, na pesquisa sobre o uso de tecnologias e condições de acesso, somente 14,54\% responderam sim, enquanto $50,8 \%$ indicaram não e outros $34,66 \%$ informaram ter dúvidas. Quanto ao cumprimento de prazos para a entrega de atividades on-line, 43,2\% afirmaram que não teriam condições, dada as limitações de acesso à internet, e 37,8\% responderam que tinham dúvidas quanto ao cumprimento. Portanto, $85,46 \%$ poderiam não participar das aulas síncronas e $81 \%$ poderiam não ter como cumprir os prazos para entrega de atividades. Em relação ao espaço físico disponível para a realização das atividades on-line, somente $37,8 \%$ responderam que possuíam condições adequadas. "A maioria dos participantes informou que não tem possibilidades de realização de atividades acadêmicas on-line ou pela ausência de ambiente adequado ou por outras dificuldades" (UFPA, 2020m, p. 12).

A pesquisa evidenciou as condições adversas dos estudantes para a realização do ERE no CUMB/UFPA, seja no que diz respeito às dificuldades de acesso à internet, seja pela falta de estrutura física adequada. Os dados denotaram que os estudantes não possuíam condições econômicas para organizar um espaço minimamente adequado para participar do ensino remoto. No entanto, apesar da situação socioeconômica dos estudantes, das dificuldades de acesso à internet e da falta de estrutura física adequada, o ERE foi aprovado na UFPA. A Resolução do Consepe 5.294/2020, substituiu os períodos 
letivos 2020.2, 2020.3 e 2020.4 pelo Período Letivo Emergencial e implantou no CUMB/UFPA o ensino remoto a partir de setembro de 2020.

Importa questionar a viabilidade da implantação do ERE num território marcado pelas desigualdades sociais e econômicas, especialmente, no que diz respeito à garantia das condições materiais de acesso aos meios necessários à implantação de tal proposta. Na seção subsequente, abordaremos as condições de estudo dos estudantes envolvidos nesse processo no CUMB/UFPA.

\section{Ensino remoto e condições de estudo no Campus Universitário do Marajó- Breves}

Com o intuito de analisarmos as condições de vida e estudo de universitários no contexto da pandemia de Covid-19, como técnica de levantamento de dados, aplicamos questionário on-line, no mês de março de 2021, para identificar as condições físicopedagógicas, o envolvimento e avaliação dos estudantes sobre o Ensino Remoto Emergencial. No presente artigo, analisamos especificamente as questões relacionadas à infraestrutura (ambiente e equipamentos), à Assistência Estudantil (Auxílios SAEST/UFPA) e à internet (meios e condições de acesso). Além de dados numéricos extraídos das questões fechadas, consideramos os registros complementares que parte dos participantes fez em questão aberta do questionário.

Foram critérios de inclusão na pesquisa: a) ser estudante de curso com oferta regular no CUMB/UFPA; b) ter sido matriculado em alguma disciplina no período 2020.4 (setembro de 2020 a fevereiro de 2021); c) ter frequentado pelo menos uma disciplina; d) ter disponibilidade e interesse em responder ao questionário. Em observância aos princípios éticos, foi assegurado o anonimato dos respondentes. O contato com os respondentes se deu inicialmente com a articulação com Coordenadores de Cursos e, em seguida, a indicação feita pelos participantes. Conforme dados de Relatório Estatístico, no período letivo 2020.4 havia 1.113 estudantes com vínculo ativo no CUMB/UFPA, sendo que 696 (62,5\%) efetivaram matrícula, logo, 417 (37,5\%) não se matricularam (UFPA, 
$2021^{13}$ ). Participaram da pesquisa 174 estudantes (25\% dos matriculados), oriundos de todos os cursos e municípios-polos do Campus ${ }^{14}$.

Destacamos algumas questões acerca do perfil dos pesquisados. Em relação à idade, 54,6\% têm entre 18 e 23 anos; 31\%, entre 24 e 30 anos; 11,5\%, entre 31 e 40 anos; 2,3\%, entre 41 e 50 anos. A maioria identificou-se sendo do sexo feminino (64,4\%). Há 83,9\% autodeclarados como negros (61,5\% pardos e $22,4 \%$ pretos). A quase totalidade dos estudantes (98,3\%) cursou escola secundária exclusivamente na rede pública e a ampla maioria (79,3\%) ingressou na UFPA via sistema de $\operatorname{cotas}^{15}$. Ainda merece destaque o fato de $42 \%$ dos estudantes terem exercido trabalho remunerado concomitante ao ERE (29,9\% durante todo período e 12,1\% em algum momento). Para 48,5\% desses, a jornada laboral foi superior a 31 horas semanais, sendo que para $29,1 \%$ foi maior que 41 horas semanais. Isso não poderia deixar de ser considerado na instituição do ERE, conforme destaca o depoimento a seguir:

Apesar das aulas serem nos horários em que já estudamos, por conta da pandemia muitas pessoas precisaram buscar outras formas de se sustentar; pessoas perderam familiares que ajudavam no sustento; pessoas perdem empregos e isso o que interfere muito na rotina e na forma de estudar. É necessário estar atento à realidade do aluno. (Estudante A, 2021. Informação escrita)

Certamente, o perfil dos discentes do CUMB/UFPA é, em grande medida, uma demonstração das características populacionais da região. A Mesorregião do Marajó, cuja riqueza é expressa na diversidade natural, apresenta precário IDH: os 16 municípios que compõem tal espaço estão entre os piores indicadores do Brasil. Isso é reflexo da ausência de políticas públicas sociais em diversos campos, como a saúde, segurança, saneamento e educação (GONÇALVES; COSTA, 2020), situação agravada no contexto pandêmico. O cenário calamitoso imposto pela Covid-19 tem efeitos mais perversos para

\footnotetext{
${ }^{13}$ Relatório Estatístico, fornecido pela Coordenação.

14 Além de Breves, sede de todas as Faculdades do Campus, participaram da pesquisa estudantes com vínculos em turmas de outros municípios: Bagre (Matemática), Cametá (Serviço Social), Melgaço (Serviço Social), Portel (Pedagogia) e Curralinho (Letras).

15 O sistema de cotas da UFPA atende à Lei n. 12.711/2012 (BRASIL, 2012); metade das vagas é destinada a oriundos da escola pública e, dessa fração, metade é para pessoas de baixa renda. Ainda na fração inicial, independente da renda, um percentual é destinado a negros e indígenas, equivalente ao percentual dessa população na Unidade Federativa. Além dessa forma de ingresso, a UFPA oferece outra ação afirmativa para indígenas, quilombolas e outras populações tradicionais via PSE (Processo Seletivo Especial).
} 
os segmentos sociais historicamente excluídos, assim, ressalta Martins (2020), fica escancarada a desigualdade social brasileira. Esse contexto nos permite presumir que os estudantes não tiveram condições materiais adequadas para frequentar aulas remotas, fato que, provavelmente, levou muitos a não se matricularem ou mesmo a desistirem das disciplinas. Os diagnósticos realizados pela própria UFPA, analisados nas seções anteriores, indicavam tal questão, acenando que muitos deixariam de frequentar as aulas caso fosse instituído o ensino remoto. Essa situação foi identificada no caso dos estudantes que se matricularam no ERE.

Comecemos por ver as questões relacionadas à infraestrutura (ambiente e equipamentos) disponível para os estudantes no ERE. Os dados apresentados no gráfico 1 evidenciam a inadequação dos equipamentos e mobiliários, bem como dos espaços físicos.

Gráfico 1: Condições ambientais e materiais de estudantes do CUMB/UFPA no ERE, 20202021

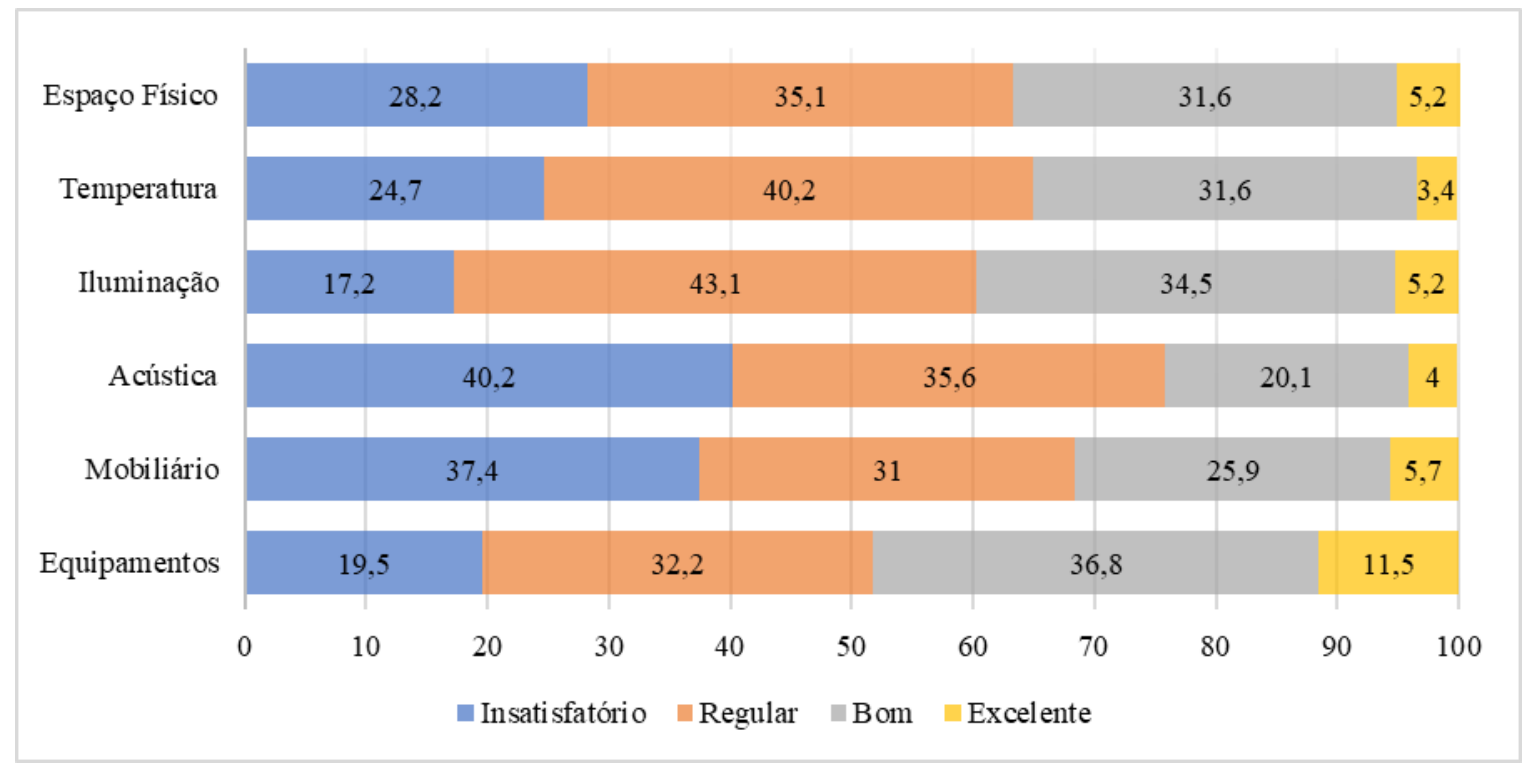

Fonte: Elaboração própria com base na pesquisa, 2021.

Em relação às questões ambientais (espaço físico, temperatura, iluminação e acústica) e ao mobiliário (mesas, cadeiras...) poucos as consideraram como "excelentes", não ultrapassando em nenhum caso 6\%. A classificação "Bom" foi, em todos os casos, inferior à avaliação Regular. Ainda que os equipamentos tenham recebido melhor avaliação, para a maioria ainda são precários. Em síntese, as condições ambientais e 
materiais foram tidas majoritariamente como insatisfatórias ou regulares - destaque para a condição de acústica com os piores índices. Essas condições refletem a realidade social e econômica dos estudantes do CUMB/UFPA e, provavelmente, de grande parcela do conjunto dos estudantes das IES públicas no Brasil.

Também buscamos averiguar o tipo e a posse dos equipamentos eletrônicos utilizados. O celular foi o aparelho amplamente mais utilizado (94,8\%), seguido pelo notebook (59,2\%). Em relação à posse, no caso do celular, a maioria $(87,4 \%)$ acessou com aparelho de uso exclusivamente pessoal e no de notebook esse indicador foi consideravelmente menor (36,8\%). Há ainda um pequeno número $(8,6 \%)$ que usou computador de mesa, sendo que para poucos $(4,6 \%)$ esse equipamento era de uso exclusivo. Tablet foi pouco usado ( $8 \%$, cuja posse exclusiva foi $6,9 \%$ ). Sobre o uso quase que exclusivo do aparelho celular para acesso à internet, e as limitações daí advindas, Marcon (2020, p. 84) faz a seguinte reflexão: "Será que os processos de ensinoaprendizagem estão sendo pensados em um contexto no qual o educando só tenha acesso à internet via telefone celular, por exemplo?" A análise dos dados nos permite identificar que somente $38,5 \%$ dos discentes tinham computador de mesa ou notebook para uso exclusivo. A grande maioria, o equivalente a $61,5 \%$, precisou dividir tais equipamentos (com familiares e terceiros) ou ainda usar apenas o celular ou o tablet para acompanhar as atividades letivas.

Nos registros de vários estudantes, identificamos questões relacionadas à infraestrutura para a implementação do ERE. Ressalta-se que a falta das condições materiais (espaço físico e equipamentos adequados) foi preponderante para que muitos se posicionassem contra o ensino remoto no CUMB/UFPA. Na mesma perspectiva outros apontaram que mesmo os discentes que possuíam equipamento para acompanhar as aulas tiveram problemas:

[...] tudo isso somado com a vontade de jogar o notebook velho pela janela, devido aos travamentos e aos bugs que duplicam as letras etc., etc., etc. (Estudante B, 2021. Informação escrita.)

No final de setembro logo após iniciar-se o ERE, meu único meio de comunicação/estudo - celular - quebrou. Logo não tive como prosseguir as aulas. Entretanto, ao conseguir um novo, tentei retomar as atividades, porém, a internet não colaborava, atrapalhando as aulas on-line e 
dificultando o acesso aos conteúdos. (Estudante C, 2021. Informação escrita)

Na efetivação do ensino remoto, muitos estudantes das IES públicas não dispõem de condições suficientes para garantir adequada formação universitária. Assim, estamos diante um processo de intensificação da precarização das condições de estudo e, consequentemente, de rebaixamento dos parâmetros de qualidade. Isso evidencia como o ensino remoto pauta-se no esvaziamento da formação e atende, primordialmente, aos interesses privado-mercantis, com a desresponsabilização estatal na garantia da educação pública. Sua perspectiva pedagógica é a mesma da educação terciária, defendida por organismo financeiros internacionais, como o BM e a OCDE. Nessa direção, o processo formativo é tido como responsabilidade individual. Trata-se da exaltação dos princípios neoliberais, com a desresponsabilização do Estado na viabilização das políticas sociais, com incentivo ao livre mercado em todas as dimensões da vida. No caso da educação, cabe a cada sujeito adquirir tal mercadoria, devendo o poder público, no limite, atuar no atendimento focalizado aos grupos mais excluídos. Assim, no caso das IES públicas, isso implica na definição de uma Assistência Estudantil fragmentada, pautada no custo/benefício, não universalista (LEITE, 2013).

Para verificar o alcance das ações de assistência promovidas pela SAEST/UFPA, no âmbito do ERE, em nossa pesquisa levantamos a abrangência desse atendimento no Campus. Identificamos que apenas $21,3 \%$ dos discentes receberam os auxílios; outros 5,7\% foram contemplados pelos editais, mas não tiveram acesso aos auxílios; também tivemos 15,5\% que demandaram auxílios, mas não foram contemplados. Por sua vez, a ampla maioria (57,4\%) sequer requereu algum auxílio. Para $17,2 \%$ dos estudantes isso se deu em função de não atenderem aos critérios exigidos; 17,8\% não tomaram conhecimento das chamadas. Há 22,4\% que tiveram ciência dos editais, atendiam aos critérios, mas não solicitaram auxílios. No último caso, entre as motivações da não solicitação, destacamos o seguinte depoimento:

Não consegui me inscrever no auxílio emergencial devido ao processo ser extremamente burocrático, cansativo e desgastante psicologicamente. (Estudante D, 2021. Informação escrita.) 
Em relação às modalidades de auxílios, 10,9\% dos estudantes foram beneficiados apenas com o "Auxílio Chip"; 2,9\% receberam somente o "Auxílio Financeiro"; 6,9\% tiveram acesso aos dois auxílios; e $0,6 \%$ (um estudante) não informou a modalidade recebida. Em síntese, a assistência estudantil específica para a inclusão digital durante o ERE na UFPA contemplou reduzido número de estudantes do CUMB, deixando a maioria fora de qualquer política. A limitação do alcance dos editais também poderá ter levado parte dos estudantes a nem mesmo reivindicar os auxílios.

Um dos maiores problemas no ERE foi não ter tido Assistência Estudantil para todos/as os/as discentes. A quantidade de Auxílios foi extremamente insuficiente. Muitas/os estudam só pelo celular e isso é muito difícil (falo por experiência própria). Além disso, estudar em casa desconcentra muito, principalmente, onde há muitas pessoas na casa. Não há ambiente silencioso adequado e etc. (Estudante E, 2021. Informação escrita)

A ausência de condições de estudo adequadas também foi identificada em relação à internet utilizada no ERE. No que diz respeito à avaliação da conexão, nenhum estudante considerou "excelente"; somente 13,2\% classificam como "bom"; para 47,1\%, é "regular"; os demais, 39,7\%, consideram "insatisfatório". Esse foi o ponto que mais recebeu comentários na questão aberta e facultada do questionário, estando presente em 32,6\% dos registros, sempre com manifestações negativas. Essa avaliação engloba as diferentes formas de conexões utilizadas, uma vez que $94,3 \%$ dos discentes tiveram acesso às aulas com internet pessoal ou familiar. No entanto, pouco mais da metade, $53,4 \%$, possuía esse serviço de forma fixa. Para $40,8 \%$ isso se deu com o uso de dados móveis. Os demais, 5,7\%, participaram das aulas apenas com outras formas de acesso (internet de vizinhos, amigos, trabalho e outros). Em função da instabilidade da conexão, os estudantes utilizaram diferentes formas de acesso. No gráfico 2, apresentamos as modalidades mais utilizadas, destacando a frequência de uso. 
Gráfico 2: Forma e frequência de acesso à internet de estudantes do CUMB/UFPA no ERE, 2020-

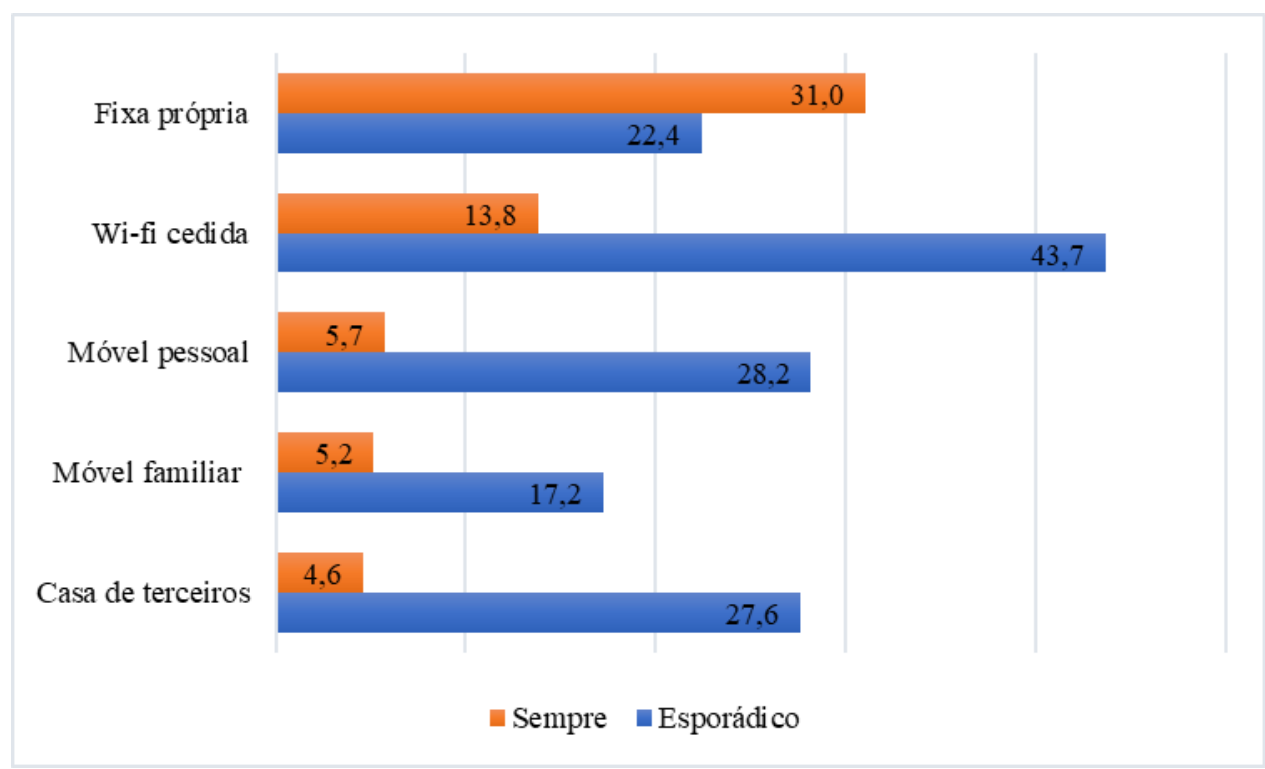

Fonte: Elaboração própria a partir da pesquisa, 2021.

Os dados confirmam a precariedade do acesso à internet. Em relação à frequência, identificamos o reduzido número de discentes que utiliza "sempre" uma determinada forma de acesso. No caso dos que têm internet fixa em casa, esse índice foi 31\%; wi-fi cedida por vizinhos registrou 13,8\%; dados móveis pessoal 5,7\%; dados móveis de outro membro da família 5,2\%; e, na casa de terceiros (outros familiares, vizinhos e amigos), $4,6 \%$.

De forma majoritária, o acesso à internet se deu, nos diferentes meios, com uso “esporádico". Destaque para wi-fi cedida com 43,7\%; em seguida vem dados móveis pessoal e casa de terceiros, respectivamente, $28,2 \%$ e $27,6 \%$; também tivemos $22,4 \%$ com internet fixa e outros $17,2 \%$ em dados móveis de outro membro familiar. O uso “esporádico", em diferentes modalidades, é certamente decorrente de dois problemas: primeiro, a falta de condições financeiras para garantir as melhores condições de acesso; segundo, a precariedade do serviço na região marajoara. Importante consideramos ainda quem indicou usar dados móveis a partir de auxílio SAEST. No computo geral foi muito incipiente a contribuição institucional para viabilizar o acesso à internet. Apenas $16,7 \%$ usou essa forma de conexão, sendo que para 6,9\% isso se deu esporadicamente. Por outro lado, para 17,2\% dos estudantes que receberam "Auxílio Chip" essa foi a única forma 
de acesso ao ensino remoto, logo, sem esse apoio seria difícil para esse grupo participar do ERE.

Desse modo, não há sentido em se ofertar ensino remoto para uma população que não tem acesso às tecnologias digitais de comunicação. Ainda que no âmbito discursivo se propague a perspectiva de inclusão ou do direito à educação, na prática se amplia a exclusão educacional. Marcon (2020, p. 82) assinala que “[...] a primeira conclusão que chegamos é de que em um contexto de isolamento social, as pessoas não possuem as mesmas condições de acesso aos computadores em seus domicílios". Neste sentido, a exclusão digital aumenta a exclusão social e vice-versa. No âmbito educacional essa exclusão é ainda maior, por isso, pensar estratégias de educação para atender as populações historicamente excluídas requer rever as formas de apropriação dos bens sociais, culturais e econômicos.

No caso do CUMB/UFPA, em síntese, a maioria dos estudantes pesquisados não teve as condições básicas de mobiliário, equipamentos e conexão à internet para cursarem disciplinas remotamente. Por sua vez, a Assistência Estudantil foi, em termos quantitativos e qualitativos, inoperante para viabilizar tais condições.

\section{Conclusão}

O estudo nos permitiu desvelar os reais objetivos da utilização do ensino remoto em substituição às atividades letivas presenciais na educação superior brasileira. As medidas instituídas por meio de legislação nacional, para sua viabilização no contexto pandêmico, preservaram os interesses do capital em seu projeto de mercantilização da educação. No âmbito do setor público, esse processo implica na precarização das condições de estudo, bem como na ampliação da exclusão educacional. Assim sendo, a alcunha de emergencial, com duração restrita à pandemia de Covid-19, serve para buscar o consenso social e, consequentemente, eliminar ou, pelo menos, desqualificar processos de resistência e, por outro lado, demostra como as orientações dos organismos multilaterais ganham materialidade na educação brasileira, que, em articulação com interesses hegemônicos internos, levam à implementação de novas políticas de formação acadêmica. 
O foco nos modos de operacionalizar o ensino com base na EaD tem a intencionalidade de definir novas referências de formação, em especial, concepções de formação associadas aos interesses político-econômicos do capital. Essa interferência representa uma nova forma de se conceber e promover a educação superior, cujo projeto envolve cortes no orçamento das Universidades Públicas e o esvaziamento da formação superior. $\mathrm{O}$ alinhamento das políticas educacionais para a educação superior brasileira às perspectivas privatistas de educação tem um custo alto para a classe trabalhadora. No afã de atender às demandas do mercado de trabalho, a formação acadêmica distancia-se dos processos formativos verdadeiramente humanos e associa-se aos processos de precarização e desumanização.

A implementação do ensino emergencial remoto não levou em consideração as desigualdades regionais e sociais dos estudantes das universidades públicas. A pesquisa em tela identificou que a efetivação do ensino remoto no CUMB/UFPA não garantiu condições adequadas de acesso e permanência aos estudantes nas atividades ofertadas no período letivo analisado. Observou-se a precarização dos processos de formação dadas as condições objetivas de acesso às tecnologias digitais, pois a maioria dos discentes dispõe apenas de aparelho de celular para acompanhar as aulas e realizar os trabalhos solicitados pelos docentes e espaços físicos inadequados para tal finalidade.

Ao selecionar e organizar um formato para a realização das atividades de ensino durante a pandemia - como alternativa viável às aulas presenciais no período póspandemia -, selecionou-se também uma concepção de formação, de sociedade, de universidade que se pretendem hegemônicas. Desse modo, a formação humana passa a ser concebida como capital humano, alinhada às demandas do mercado de trabalho, tornando-se um instrumento de dominação social, cultural e política.

\section{Referências}

ADUFPA. Associação dos Docentes da Universidade Federal do Pará. Porque somos contra o retorno às atividades presenciais e ao ensino remoto na UFPA. Belém, PA: ADUFPA, 31 jul. 2020. Disponível em: http://www.adufpa.com.br/site/index.php/documentos/download/2-diversos/7-porquesomos-contra-o-retorno-as-atividades-presenciais-e-ao-ensino-remoto-na-ufpa. Acesso em: 29 mar. 2021. 
BRASIL. Lei n. 12.711, de 29 de agosto de 2012. Dispõe sobre o ingresso nas universidades federais e nas instituições federais de ensino técnico de nível médio e dá outras

providências. Diário Oficial da União: seção 1, Brasília, DF, ano 149, n. 169, p. 1-2, 30 ago. 2012. Disponível em:

https://pesquisa.in.gov.br/imprensa/jsp/visualiza/index.jsp?jornal=1\&pagina=1\&data=30/08 /2012\&totalArquivos=120. Acesso em: 10 mar. 2021.

BRASIL. Emenda Constitucional No 95, de 15 de dezembro de 2016. Altera o Ato das Disposições Constitucionais Transitórias, para instituir o Novo Regime Fiscal, e dá outras providências. Diário Oficial da União: seção 1, Brasília, DF, ano 153, n. 241, p. 2-3, 16 dez. 2016. Disponível em: https://pesquisa.in.gov.br/imprensa/jsp/visualiza/index.jsp?data=16/12/2016\&jornal=1\&pagi na=1\&totalArquivos=368. Acesso em: 10 mar. 2021.

BRASIL. Ministério da Educação. Portaria n 2.117, de 6 de dezembro de 2019. Dispõe sobre a oferta de carga horária na modalidade de Ensino a Distância - EaD [...]. Diário Oficial da União: seção 1, Brasília, DF: Ministério da Educação, ano 157, n. 239, p.131, 11 dez. 2019. Disponível em: https://www.in.gov.br/en/web/dou/-/portaria-n-2.117-de-6-dedezembro-de-2019-232670913. Aceso em: 15 abr. 2021.

BRASIL. Ministério da Educação. Portaria n 343 , de 17 de março de 2020. Dispõe sobre a substituição das aulas presenciais por aulas em meios digitais [...]. Diário Oficial da União: seção 1, Brasília, DF: Ministério da Educação, ano 158, n. 53, p.39, 18 mar. $2020 a$.

Disponível em:

https://pesquisa.in.gov.br/imprensa/jsp/visualiza/index.jsp?data=18/03/2020\&jornal=515\&p agina=39\&totalArquivos=125. Acesso em: 12 abr. 2021.

BRASIL. Ministério da Educação. Portaria $n^{\circ} 345$, de 19 de março de 2020. Altera a Portaria $\mathrm{n}^{\circ}$ 343, de 17 de março de 2020. Diário Oficial da União: seção 1, Brasília, DF: Ministério da Educação, ano 158, n. 54-D, p.1, 19 mar. 2020b. Disponível em:

https://pesquisa.in.gov.br/imprensa/jsp/visualiza/index.jsp?jornal=603\&pagina=1\&data=19/ 03/2020\&totalArquivos=1. Acesso em: 12 abr. 2021.

BRASIL. Ministério da Educação. Portaria $\mathrm{n}^{\circ}$ 395, de 15 de abril de 2020. Prorroga o prazo previsto no $\S 1^{\circ}$ do art. $1^{\circ}$ da Portaria $n^{\circ} 343$, de 17 de março de 2020. Diário Oficial da União: seção 1, Brasília, DF: Ministério da Educação, ano 158, n. 73, p. 61, 16 abr. 2020 c. Disponível em:

https://pesquisa.in.gov.br/imprensa/jsp/visualiza/index.jsp?data=16/04/2020\&jornal=515\&p agina $=61$. Acesso em: 12 abr. 2021

BRASIL. Ministério da Educação. Portaria n 473, de 12 de maio de 2020. Prorroga o prazo previsto no $\S 1^{\circ}$ do art. $1^{\circ}$ da Portaria $n^{\circ} 343$, de 17 de março de 2020. Diário Oficial da União: seção 1, Brasília, DF, ano 158, n. 90, p. 55, 13 maio 2020d. Disponível em: https://pesquisa.in.gov.br/imprensa/jsp/visualiza/index.jsp?data=13/05/2020\&jornal=515\&p agina=55\&totalArquivos=123. Acesso em: 12 abr. 2021.

BRASIL. Ministério da Educação. Portaria $n^{\circ}$ 544, de 16 de junho de 2020. Dispõe sobre a substituição das aulas presenciais por aulas em meios digitais, [...] e revoga as Portarias MEC $n^{\circ} 343$, de 17 de março de 2020, $n^{\circ} 345$, de 19 de março de 2020, e $n^{\circ} 473$, de 12 de 
maio de 2020. Diário Oficial da União: seção 1, Brasília, DF: Ministério da Educação, ano 158, n. 114, p.62, 17 jun. 2020e. Disponível em:

https://pesquisa.in.gov.br/imprensa/jsp/visualiza/index.jsp?data=17/06/2020\&jornal=515\&p agina=62. Acesso em: 12 abr. 2021.

BRASIL. Ministério da Educação. Portaria n 1.030, de 01 de dezembro de 2020. Dispõe sobre o retorno às aulas presenciais e sobre caráter excepcional de utilização de recursos educacionais digitais [...] enquanto durar a situação de pandemia do novo coronavírus Covid-19. Diário Oficial da União: seção 1, Brasília, DF, ano 158, n. 230, p. 55, 2 dez. 2020 of. Disponível em:

https://pesquisa.in.gov.br/imprensa/jsp/visualiza/index.jsp?data=02/12/2020\&jornal=515\&p agina $=55$. Acesso em: 12 abr. 2021.

BRASIL. Ministério da Educação. Portaria $\mathrm{n}^{\circ}$ 1.038, de 7 de dezembro de 2020. Altera a Portaria $M E C n^{\circ}$ 544, de 16 de junho de 2020, que dispõe sobre a substituição das aulas presenciais por aulas em meio digitais, enquanto durar a situação de pandemia do novo coronavírus - Covid-19, e a Portaria MEC $\mathrm{n}^{\circ}$ 1.030, de $1^{\circ}$ de dezembro de 2020, que dispõe sobre o retorno às aulas presenciais [...]. Diário Oficial da União: seção 1, Brasília, DF, ano 158, n. 233-A, p. 1, 7 dez. 2020g. Disponível em:

https://pesquisa.in.gov.br/imprensa/jsp/visualiza/index.jsp?data=07/12/2020\&jornal=600\& pagina=1. Acesso em: 12 abr. 2021.

BRASIL. Ministério da Educação. Conselho Nacional de Educação. Parecer CNE/CP n ${ }^{\circ}$ 5/2020, aprovado em 28 de abril de 2020. Reorganização do Calendário Escolar e da possibilidade de cômputo de atividades não presenciais [...]. Brasília, DF, Conselho Nacional de Educação, 28 abr. 2020h. Disponível em:

http://portal.mec.gov.br/index.php?option=com_docman\&view=download\&alias=14511pcpo05-20\&category_slud=marco-2020-pdf\&Itemid=30192. Acesso em: 12 abr. 2021.

BRASIL. Medida Provisória $N^{\circ} 934$, de $1^{\circ}$ de abril de 2020. Estabelece normas excepcionais sobre o ano letivo da educação básica e do ensino superior decorrentes das medidas para enfrentamento da situação de emergência de saúde pública de que trata a Lei $n^{\circ}$ 13.979, de 6 de fevereiro de 2020. Diário Oficial da União: seção 1, Brasília, DF, ano 158, n. 63-A, p. 1, 1 abr. 2020i. Disponível em:

https://pesquisa.in.gov.br/imprensa/jsp/visualiza/index.jsp?data=01/04/2020\&jornal=600\& pagina=1. Acesso em: 12 abr. 2021.

BRASIL. Ministério da Educação. Lei n 14.040/2020, de 18 de agosto de 2020. Estabelece normas educacionais excepcionais a serem adotadas durante o estado de calamidade pública reconhecido pelo Decreto Legislativo $n^{\circ} 6$, de 20 de março de 2020; e altera a Lei $\mathrm{n}^{\circ}$ 11.947, de 16 de junho de 2009. Diário Oficial da União: seção 1, Brasília, DF, ano 158, n. 159, p. 4, 19 ago. 2020j. Disponível em:

https://pesquisa.in.gov.br/imprensa/jsp/visualiza/index.jsp?data=19/08/2020\&jornal=515\&p agina=1\&totalArquivos=116. Acesso em: 12 abr. 2021.

BRASIL. Ministério da Educação. Conselho Nacional de Educação. Parecer CNE/CP n ${ }^{\circ}$ 19/20, de 08 de dezembro de 2020. Reexame do Parecer CNE/CP n ${ }^{\circ} 15$, de 6 de outubro de 2020 [...]. Brasília, DF, Conselho Nacional de Educação., 08 dez. 2020k. Disponível em: 
http://portal.mec.gov.br/index.php?option=com_docman\&view=download\&alias=167131pcp019-20\&category_slug=dezembro-2020-pdf\&Itemid=30192. Acesso em: 17 abr. 2021.

BRASIL. Ministério da Educação. Conselho Nacional de Educação. Resolução $C N E / C P n^{\circ} 2$, de 10 de dezembro de 2020. Institui Diretrizes Nacionais orientadoras para a implementação dos dispositivos da Lei n 14.040, de 18 de agosto de 2020 [...]. Diário Oficial da União: seção 1, Brasília, DF: Conselho Nacional de Educação, ano 158, n. 237, p. 52-55, 11 dez. 2020l. Disponível em: https://www.in.gov.br/en/web/dou/-/resolucao-cne/cpn-2-de-10-de-dezembro-de-2020-293526006. Acesso em: 17 abr. 2021.

BRASIL. Ministério da Saúde. Secretaria de Vigilância de Saúde. Painel de casos de doença pelo coronavírus 2019 (COVID-19) no Brasil pelo Ministério da Saúde. Painel Coronavírus, [Brasília: O Ministério], 2021. Disponível em: https://covid.saude.gov.br/. Acesso em: 12 abr. 2021.

CETIC.BR. Centro Regional de Estudos para o Desenvolvimento da Sociedade da Informação. TIC Domicílios 2019: principais resultados. [São Paulo: CETIC], 2019. Disponível em: https://cetic.br/media/analises/tic_domicilios_2019_coletiva_imprensa.pdf. Acesso em: 14 abr. 2020.

CHAVES, Vera Lúcia Jacob. Expansão da privatização/mercantilização do ensino superior Brasileiro: a formação dos oligopólios. Educação \& Sociedade [online], Campinas, v.31, n. 111, p. 481-500, abr./jun. 2010. Disponível em:

https://www.scielo.br/scielo.php?script=sci_arttext\&pid=S0101-73302010000200010. Acesso em: 12 abr. 2021.

CHAVES, Vera Lúcia Jacob; SANTOS, Maria Rosimary Soares; KATO, Fabíola Bouth Grello. Financiamento público para o ensino superior privado-mercantil e a financeirização.

Jornal de Políticas Educacionais, [Curitiba], v. 14, n. 08, p. 1-20, jan. 2020. Disponível em: https://revistas.ufpr.br/jpe/article/view/70063/40309. Acesso em: 20 dez. 2020.

Estudante A. [Registro em questionário on-line da pesquisa] Avaliação de estudantes da UFPA/CUMB sobre o Ensino Remoto Emergencial, 14 mar. 2021.

Estudante B. [Registro em questionário on-line da pesquisa] Avaliação de estudantes da UFPA/CUMB sobre o Ensino Remoto Emergencial, 20 mar. 2021.

Estudante C. [Registro em questionário on-line da pesquisa] Avaliação de estudantes da UFPA/CUMB sobre o Ensino Remoto Emergencial, 20 mar. 2021.

Estudante D. [Registro em questionário on-line da pesquisa] Avaliação de estudantes da UFPA/CUMB sobre o Ensino Remoto Emergencial, 25 mar. 2021.

Estudante E. [Registro em questionário on-line da pesquisa] Avaliação de estudantes da UFPA/CUMB sobre o Ensino Remoto Emergencial, 27 mar. 2021.

EVANGELISTA, Olinda et al. Desventuras dos professores na formação para o capital. Campinas: Mercado de Letras, 2019. 
GONÇALVES, Andressa Santos; COSTA, Eliane Miranda. Revista Humanidades e Inovação, Palmas, v.7, n.15, p. 508-523, 2020. Disponível em:

https://revista.unitins.br/index.php/humanidadeseinovacao/article/view/2925. Acesso em: 17 abr. 2021.

HARVEY, David. O Neoliberalismo: história e implicações. São Paulo: Edições Loyola, 2008.

INEP. Instituto Nacional de Estudos e Pesquisas Educacionais Anísio Teixeira (INEP).

Resultados. Brasília: INEP, 2020. Disponível em: https://www.gov.br/inep/pt-br/areas-deatuacao/pesquisas-estatisticas-e-indicadores/censo-da-educacao-superior/resultados. Acesso em: 12 abr. 2021.

LEITE, Janete Luzia. Política de Assistência Estudantil: direito da carência ou carência de direitos? SER Social, Brasília, v. 14, n. 31, p. 453-472, jul./dez. 2012. Disponível em: https://periodicos.unb.br/index.php/SER_Social/article/view/13024. Acesso em: 17 abr. 2021.

MANCEBO, Deise; VALE, Andréa Araújo do; MARTINS, Tânia Barbosa. Políticas de expansão da educação superior no Brasil 1995-2010. Revista Brasileira de Educação, Rio de Janeiro, v. 20 n. 60, p. 31-50, jan./mar. 2015. Disponível em:

https://www.scielo.br/pdf/rbedu/v20n60/1413-2478-rbedu-20-60-0031.pdf. Acesso em: 2 jul. 2020.

MARCON, Karina. Inclusão e exclusão digital em contextos de pandemia: que educação estamos praticando e para quem? Criar Educação, Criciúma, v. 9, n. 2, p. 80-103, 2020. Edição Especial. Disponível em:

http://periodicos.unesc.net/criaredu/article/view/6047/5401. Acesso em: 12 abr. 2021.

MARTINS, Mônica Dias. A pandemia expõe de forma escancarada a desigualdade social. [S.l.]: La Biblioteca Acceso ABierto, 2020. Disponível em: https://www.clacso.org/wpcontent/uploads/2020/05/Dias-Martins.pdf. Acesso em: 17 abr. 2021.

MARX, Karl. O capital: crítica da economia política: volume 1, livro primeiro: o processo de produção do capital. São Paulo: Abril Cultural, 1984. Tomo 2.

MAUÉS, Olgaíses Cabral. Ensino superior na ótica dos organismos internacionais. Educar em Revista, Curitiba, v. 35, n. 75, p. 13-30, maio/jun. 2019. Disponível em: https://revistas.ufpr.br/educar/article/view/66009/39096. Acesso em: 20 maio 2020.

MÉSZÁROS, István. A crise estrutural do capital. São Paulo: Boitempo, 2009.

MOREL, Ana Paula Massader. Negacionismo da Covid-19 e educação popular em saúde: para além da necropolítica. Trabalho, Educação e Saúde, Rio de Janeiro, v. 19, e00315147, jan. 2021. DOI: 10.1590/1981-7746-solo0315. Disponível em:

https://www.scielo.br/pdf/tes/v19/0102-6909-tes-19-e00315147.pdf. Acesso em: 12 abr. 2021. 
OPAS. Organização Pan-Americana de Saúde. Histórico da pandemia de COVID-19. [S.I.]: OPAS, 2021. Disponível em: https://www.paho.org/pt/covid19/historico-da-pandemiacovid-19. Acesso em: 12 abr. 2021.

SGUISSARDI, Valdemar. Universidade brasileira no século XXI: desafios do presente. São Paulo: Cortez, 2009.

REIS, Luiz Fernando; MACÁRIO, Epitácio. Dívida pública e financiamento das universidades federais e da ciência e tecnologia no brasil (2003-2020). Revista Práxis Educacional, Vitória da Conquista, Bahia-Brasil, v.16, n. 41, p. 20-46, Edição Especial, 2020. Disponível em: https://periodicos2.uesb.br/index.php/praxis/article/view/7243/5076. Acesso em 12 abr. 2021.

UFPA. Universidade Federal do Pará. Pró-Reitoria de Planejamento. Coordenadoria de Pesquisa Institucional. UFPA em números 2020: ano base 2019. [Belém]: UFPA, 2020a. Disponível em: http://www.ufpanumeros.ufpa.br/. Acesso em: 14 abr. 2021.

UFPA. Universidade Federal do Pará. UFPA instala Grupo de Trabalho sobre o novo coronavírus e divulga recomendações. [Belém]: UFPA, 13 mar. 2020. [Belém]: UFPA, 2020b. Disponível em: https://portal.ufpa.br/index.php/ultimas-noticias2/11446-ufpainstala-grupo-de-trabalho-sobre-o-novo-corona-virus-e-divulga-recomendacoes. Acesso em: 03 abr. 2021

UFPA. Universidade Federal do Pará. Resolução n 5.291, de 22 de maio de 2020. Aprova a suspensão do Calendário Acadêmico da UFPA [...]. Belém, PA: Conselho Superior de Ensino Pesquisa e Extensão, 2020c. Disponível em: https://sege.ufpa.br/boletim_interno/downloads/resolucoes/consepe/2020/Resolucao_52 91_2020_CONSEPE.pdf. Acesso em 14 mar. 2021.

UFPA. Universidade Federal do Pará. Consepe mantém suspensão das atividades presenciais na UFPA. [Belém]: UFPA, 25 maio 2020d. Disponível em:

https://portal.ufpa.br/index.php/ultimas-noticias2/11608-consepe-mantem-suspensao-dasatividades-presenciais-na-ufpa. Acesso em: 03 abr. 2021.

UFPA. Universidade Federal do Pará. Centro de Tecnologia da Informação e Comunicação (CTIC). Relatório de quantidade de respostas por alternativa. [Belém]: UFPA, 14 ago. 2020e.

UFPA. Universidade Federal do Pará. PROEG divulga pesquisa sobre condições de acesso digital dirigida aos discentes e docentes em tempos de pandemia da Covid-19. Belém, PA: [UFPA], 27 jul. 2020f. Disponível em: https://portal.ufpa.br/index.php/ultimasnoticias2/11779-proeg-divulga-pesquisa-sobre-condicoes-de-acesso-digital-dirigida-aosdiscentes-e-docentes-em-tempos-de-pandemia-da-covid-19. Acesso em 03 abr. 2021

UFPA. Universidade Federal do Pará. Resolução N. 5.294, de 21 de agosto de 2020. Aprova, de forma excepcional e temporária, o Ensino Remoto Emergencial [...]. Belém, PA: Conselho Universitário, 2020g. Disponível em: http://proeg.ufpa.br/images/Artigos/Normas/Resolucao_5294_2020_CONSEPEAprovaoER EnaUFPA.pdf. Acesso em: 03 mar. 2021. 
UFPA. Universidade Federal do Pará. Superintendência de Assistência Estudantil. Edital No 06/2020 - SAEST/UFPA - Auxílios emergenciais de apoio à inclusão digital. [Belém]:

UFPA, 2020h. Disponível em:

https://www.saest.ufpa.br/portal/images/Editais/2020.06.AUXILIOS.DE.INCLUSAO.DIGITA L.pdf. Acesso em: 03 mar. 2021.

UFPA. Universidade Federal do Pará. Superintendência de Assistência Estudantil. SIGAEst. Escolha o Auxílio que deseja visualizar a lista de deferimento. [Belém]: UFPA, 2020i. Disponível em: https://sigaest.ufpa.br/sigaest/listas/. Acesso em: 03 mar. 2021.

UFPA. Universidade Federal do Pará. Superintendência de Assistência Estudantil. Edital No 10/2020 - SAEST/UFPA - Auxílio emergencial de apoio à inclusão digital - CHIP. [Belém]: UFPA, 2020j. Disponível em:

https://www.saest.ufpa.br/portal/images/Editais/2020.10.AUXILIO.DE.INCLUSAO.DIGITAL. CHIP.pdf. Acesso em: 03 mar. 2021.

UFPA. Universidade Federal do Pará. Superintendência de Assistência Estudantil. Edital No 07/2020 - SAEST/UFPA - Edital de seleção pública para concessão de auxílio Kit PCD de Tecnologia Assistiva. [Belém]: UFPA, 2020k. Disponível em:

https://www.saest.ufpa.br/portal/images/Editais/2020.07.KIT.PCD.Retificado.pdf. Acesso em: 03 mar. 2021.

UFPA. Universidade Federal do Pará. Superintendência de Assistência Estudantil. Edital $\mathbf{N}^{\circ}$ 09/2020 - SAEST/UFPA - Edital de seleção pública para concessão de auxílio Kit PCD de Tecnologia Assistiva II. [Belém]: UFPA, 2020l. Disponível em: https://www.saest.ufpa.br/portal/images/Editais/2020.09.KIT.PCD.II.pdf. Acesso em: 03 mar. 2021.

UFPA. Universidade Federal do Pará. Campus Universitário do Marajó-Breves. Disponível em: Relatório de aplicação do questionário a discentes do CUMB (usos de tecnologias e acesso à Internet). [Belém]: UFPA, 2020m. Disponível em:

http://www.campusbreves.ufpa.br/images/documentos_institucionais/02.-Relatrio-Usosde-tecnologias-e-acesso--Internet---Discentes-do-CUMB.p̄pdf. Acesso em: 15 mar. 2021.

Recebido em: 18/04/2021 Aprovado em: 06/05/2021

Universidade do Estado de Santa Catarina - UDESC Programa de Pós-Graduação em Educação - PPGE Revista Linhas

Volume 22 - Número 49 - Ano 2021 revistalinhas@gmail.com 